\title{
Preparação e atuação dos professores do ensino primário face aos desafios da atenção à diversidade no contexto da sala de aula no Município do Soyo ${ }^{1}$
}

Preparation and performance of primary school teachers in the face of the challenges of attention to diversity in the context of the classroom in the Municipality of Soyo

Preparación y desempeño de los profesores de la enseñanza primaria ante los desafíos de atención a la diversidad en el contexto del aula en el Municipio de Soyo

António António

Doutorando na Universidade do Estado de Santa Catarina, Florianópolis, SC, Brasil

E-mail: antoniotonny1988@hotmail.com ORCID: https://orcid.org/0000-0001-7573-1885

Caroll Alejandra Schilling Lara

Professora doutora da Universidad Católica del Maule, Talca, Maule, Chile

E-mail: cas11975@gmail.com ORCID: https://orcid.org/0000-0002-9047-6306

Osvaldo Hernández González

Doutorando na Universidad de Talca, Talca, Maule, Chile

E-mail: osvaldo.hernandez@utalca.cl ORCID: https://orcid.org/0000-0002-1319-6167

Recebido em 12 de abril de 2020

Aprovado em 06 de maio de 2021

Publicado em 27 de maio de 2021

\section{RESUMO}

Esta pesquisa procura compreender o estado atual da preparação de professores do ensino primário ${ }^{2}$ no que diz respeito à diversidade em salas de aula no Município do Soyo, província do Zaire, Angola. Foi realizada a partir de um paradigma qualitativo, uma abordagem fenomenológica baseada em um estudo de elcance exploratório. A pesquisa procura responder à seguinte questão: Qual é o estado atual de preparação que os professores do ensino básico apresentam em relação à atenção à diversidade em sala de aula no Município do Soyo, província do Zaire, Angola? Foi utilizada uma amostra não probabilística de critérios intencionais, onde foram selecionados 12 professores de três escolas, sendo 6 com formação inicial de professores e 6 sem formação inicial. Para a coleta de informações, foram utilizadas duas técnicas: a entrevista semiestruturada para professores com formação inicial e o grupo focal para professores sem formação inicial. Foi aplicada a técnica de análise de conteúdos ao processo de análise de resultados.Os resultados da pesquisa mostram fragilidades no conhecimento e na gestão da diversidade em sala de aula e diferenças substanciais entre os professores com formação inicial e sem formação inicial analisados a partir das categorias de análise a priori e emergente. 
http://dx.doi.org/10.5902/1984686X63446

Palavras-chave: Atenção à diversidade, inclusão educacional, formação de professores, Município do Soyo.

\section{ABSTRACT}

This research seeks to understand the current state of preparation of teachers of primary education with respect to diversity in classrooms in the Municipality of Soyo, Zaire province, Angola. It was carried out from a qualitative paradigm, a phenomenological approach based on a study of exploratory scope. The research seeks to answer the following question: What is the current state of preparedness that primary school teachers present regarding attention to diversity in the classroom in the Municipality of Soyo, Zaire province, Angola? A non-probabilistic sample of intentional criteria was used, where 12 teachers from three schools were selected, 6 of them with initial teacher training and 6 without initial training. For the collection of information, two techniques were used: the semi-structured interview for teachers with initial training and the focus group for teachers without initial training. The technique of content analysis was applied to the process of analyzing results. The results of the research show weaknesses of knowledge and management of classroom diversity and substantial differences between teachers with initial training and without initial training analyzed from the categories of a priori and emerging analysis.

Keywords: Attention to diversity, educational inclusion, teacher training, Municipality of Soyo.

\section{RESUMEN}

La presente investigación busca comprender el estado actual de preparación de los profesores de la enseñanza de enseñanza primaria respecto atención a la diversidad en sala de clase en el Municipio de Soyo, provincia de Zaire, Angola. Se realizó desde un paradigma cualitativo, enfoque fenomenológico a partir de un estudio de alcance exploratorio. La investigación busca responder la siguiente pregunta: ¿Cuál es el estado actual de preparación que los profesores de enseñanza primaria presentan respecto atención a la diversidad en sala de clase en el Municipio de Soyo, provincia de Zaire, Angola? Se utilizó una muestra no probabilística de criterio intencional, donde fueron seleccionados 12 profesores de tres escuelas, 6 de ellos con formación inicial del profesorado y otros 6 sin formación inicial. Para la recolección de informaciones, fueron utilizadas dos técnicas: la entrevista semiestructurada para los profesores con formación inicial y el grupo focal para los profesores sin formación inicial. Se aplicó para el proceso de análisis de resultados, la técnica de análisis de contenido. Los resultados de la investigación evidencian debilidades de conocimiento y manejo de la diversidad en sala de clase y diferencias substanciales entre profesores con formación inicial y sin formación inicial analizados desde las categorías de análisis apriorísticas y emergentes.

Palabras-clave: Atención a la diversidad, inclusión educativa, formación docente, Municipio de Soyo. 
http://dx.doi.org/10.5902/1984686X63446

\section{Introdução}

Estudos sobre a diversidade em contexto educativo remontam há décadas e vêm ganhando espaço gradativamente nas discussões acadêmicas e fazendo cada vez mais parte da gestão das organizações educacionais, mais avançado em países com maiores índices de desenvolvimento e menos avançado em países subdesenvolvidos. Definir a diversidade é um desafio complexo, pois se caracteriza por sua amplitude, seu caráter multifatorial (envolvendo questões individuais, sociais e relacionais) e pela multidisciplinaridade de sua abordagem.

Diante da complexidade do que se entende por diversidade, alguns pesquisadores buscam encontrar uma aproximação da definição de acordo com um paradigma específico em um contexto próprio. Segundo Bergeron (2008), a diversidade refere-se ao grande número de experiências e atributos que contribuem para a singularidade de cada pessoa, independentemente de sua herança, comunidade cultural ou étnica. Outros autores tentam facilitar a compreensão deste conceito ao defini-lo como características que se referem a indivíduos únicos e diferentes (GIMENO, 2000). Tal como sugere Ruíz Quiroga (2010 p. 2): "a atenção à diversidade é um conceito amplo que inclui dificuldades de aprendizagem, deficiências físicas, mentais e sensoriais, grupos de risco, minorias étnicas, etc. A diversidade é uma realidade observável, inerente ao ser humano".

O conceito de diversidade sugere que todos os alunos têm necessidades educativas individuais próprias e específicas a fim de acessar as experiências de aprendizagem necessárias à sua socialização estabelecidas no currículo escolar. Este prinícipio encontrase também ressaltado no Decreto Presidencial n 187/17 de 16 Agosto, que aprova a Política Nacional de Educação Especial Orientada para a Inclusão Escolar que defende uma escola aberta à diversidade (ANGOLA, 2017).

As pessoas diferem em muitas outras dimensões e que a identidade de cada uma delas é determinada por pertencer a certos grupos. Aceitar essas premissas nos leva a reconhecer que a diversidade na sala de aula deve ser considerada não apenas em termos dos diferentes grupos culturais presentes nela, ou de crianças com necessidades educativas especiais, mas também nas áreas de diversidade que compõem as identidades dos alunos, todos que lá estão, vivem e trabalham (BARRIO DE LA PUENTE, 2088, p. 15). O foco da pesquisa vaí além da deficiência e das necessidades educativas especiais, nossa perspectiva de diversidade contempla as mais variadas diferenças que podem, direta ou indiretamente influênciar o processo de aprendizagem do aluno. 
http://dx.doi.org/10.5902/1984686X63446

$\mathrm{Na}$ Lei de Bases do Sistema de Educação e Ensino, Lei n 17/16, de 07 de outubro, que em 2020 foi alterada e atualizada com a Emenda Lei 32/20 de 12 de agosto, contempla num dos princípios fundamentais consagrado no artigo $9^{\circ}$, a universalidade da educação e do ensino, segundo o qual, o Sistema de Educação e Ensino tem carácter universal, pelo que, todos os indivíduos têm iguais direitos no acesso, na frequência e no sucesso escolar nos diversos níveis de ensino, desde que sejam observados os critérios de cada Subsistema de Ensino, assegurando a inclusão social, a igualdade de oportunidades e a equidade, bem como a proibição de qualquer forma de discriminação (ANGOLA, 2016).

Uma reflexão importante feita por Artiles e Kozleski (2019) considera que se a educação inclusiva aspira em mudar sistemas educativos buscando melhorar o acesso, a participação e os resultados para todos os estudantes, independentemente de qualquer forma de diferença que os estudantes supostamente incorporem, é paradoxal que reformas educativas politicamente proposta para atender todos os alunos seja implementado com foco nas pessoas com deficiência.

Diante das atuais tendências e desafios da educação no século $X X I$, a atenção à diversidade vem conhecendo uma mudança de paradigma fazendo mais ênfase numa abordagem baseada em direitos humanos. Por conta disso, o acompanhamento desta dinâmica através da definição e implementação de políticas educativas de cada país face à inclusão se veem condicionado por vários fatores atendendo um contexto próprio. Um dos principais problemas que a educação angolana enfrenta atualmente diante dos desafios que demandam atenção à diversidade é a formação de professores para responder de modo eficiente e eficaz à heterogeneidade na sala de aula e às necessidades individuais de cada aluno. É a partir desta base que a pesquisa se propõe responder à seguinte questão: Qual é preparação que os professores do ensino básico apresentam em relação ao atendimento da diversidade na sala de aula no Município do Soyo, província do Zaire, Angola?

Em geral, é importante entender a diversidade, uma vez que a coexistência com base nas diferenças é geralmente difícil para os seres humanos. Especificamente no campo da educação, respectivamente para o ensino primário, permite estabelecer apoio regular do grupo, conformação de grupos flexíveis, adaptações significativas do currículo, medidas de apoio, reforço fora do horário escolar e plano específico e individualizado de reforço ou recuperação (ARAQUE e BARRIO DE LA PUENTE, 2010). Em Angola, não existem antecedentes de pesquisa sobre atenção à diversidade, este deficit faz da pesquisa uma 
http://dx.doi.org/10.5902/1984686X63446

iniciativa relevante e importante para a criação de uma consciência inclusiva nos agentes da educação.

Daí, o objetivo da pesquisa é compreender o estado atual da preparação dos professores do ensino primário no que diz respeito a atenção à diversidade na sala de aula.

\section{Metodologia da pesquisa}

Esta pesquisa obedeceu a uma abordagem interpretativa, foi realizada a partir de um desenho fenomenológico, cujo objetivo principal é explorar, descrever e compreender as experiências das pessoas com relação a um fenômeno e descobrir os elementos comuns de tais experiências (HERNÁNDEZ, FERNANDEZ e BAPTISTA , 2014). A pesquisa é do tipo exploratório na qual se pretende compreender o estado atual de preparação de professores do ensino primário sobre a atenção à diversidade em contexto da sala de aula no Município do Soyo.

Contou-se com uma amostra de 12 professores de três escolas primárias do Município do Soyo, entre elas, duas são de ensino público estatal e uma do ensino público privado. Os participantes foram organizados em dois grupos: um grupo de 6 professores para a entrevista individual semiestruturada e outro de 6 professores para o grupo focal. O motivo fundamental pelo qual se optou por essa diferenciação nos instrumentos e procedimentos de coleta de informações está meramente baseado em condições de comodidade dos participantes. Experiências com os trabalhos finais de cursos das licenciaturas levam a perceção de que os professores com formação inicial tendem a estar mais confiantes em participar das pesquisas, provavelmente por conta da formação prévia com a qual contam, por outro lado, acontece o contrário com os professores sem formação inicial que dificilmente se predispõem a esses eventos de pesquisa, demonstrando um certo receio de não estar a altura de responder às informações requeridas para a pesquisa.

Por isso, com base aos possíveis receios e falta de confiança por parte desses, pensouse num grupo focal que facilitasse a interação dos participantes e proporcionasse um ambiente amigável para todos. Conforme enfatiza Alberto (2005, p.281):

O ambiente proporcionado pela organização do grupo focal permite interação entre os membros do grupo; as informações prestadas por um dos integrantes estimulam os demais a falar sobre o assunto; o debate entre eles enriquece a qualidade das informações; o fato de se encontrar um grupo de iguais dá mais segurança ao participante para expressar suas opiniões, com respostas mais espontâneas e genuínas. 
http://dx.doi.org/10.5902/1984686X63446

Daí, para a entrevista individual semiestruturada, participaram professores com formação inicial de professores e, no grupo focal, professores sem formação inicial de professores. Utilizou-se amostragem não probabilística, como argumenta (Hernández, Fernandez e Baptista (2014), o procedimento não é mecânico nem baseado em fórmulas probabilísticas, mas depende do processo decisório de um pesquisador ou grupo de pesquisadores. A partir daí, os participantes foram selecionados com base em um critério intencional em que os participantes são escolhidos com base em julgamentos préestabelecidos pelo pesquisador (ARIAS, 2012).

O processo de seleção de participantes contou com os seguintes critérios de inclusão:

$\checkmark$ As escolas devem estar entre as melhores em termos de infraestrutura, devem estar localizadas no centro da cidade e ter recursos humanos e materiais que os distinguem em comparação com outras;

$\checkmark$ Ser professor de uma das três escolas primárias escolhidas para pesquisa;

$\checkmark$ Ter formação inicial de professor para participar da entrevista;

$\checkmark$ Não ter formação inicial de professor para participar do grupo focal;

$\checkmark$ Ser professor com experiência igual ou superior a 5 anos;

$\checkmark$ Aceitar a participação voluntária da investigação.

Tabela 1 - Distribuição dos participantes por categoria de formação

\begin{tabular}{|c|c|c|c|}
\hline Instituição educativa & Docentes & $\begin{array}{c}\text { Com formação inicial de } \\
\text { professores }\end{array}$ & $\begin{array}{c}\text { Sem formação inicial } \\
\text { de professores }\end{array}$ \\
\hline IE 1 & 4 & 2 & 2 \\
\hline IE2 & 4 & 2 & 2 \\
\hline IE3 & 4 & 2 & 6 \\
\hline Total & 12 & 6 & 2 \\
\hline
\end{tabular}

Fonte: Campo de investigação (2018).

Foram aplicados para a coleta de dados entrevista semiestrutarada para professores com formação inicial. Assume-se a entrevista desde Díaz-Bravo (2013), que a considera como a comunicação interpessoal estabelecida entre o pesquisador e o sujeito da pesquisa, a fim de obter respostas verbais às questões levantadas sobre o problema proposto. Também é definida a partir de Hernández, Fernández \& Baptista (2014) como uma reunião para discutir e trocar informações entre uma pessoa (o entrevistador) e outra (o entrevistado) ou outros (entrevistados). Outro instrumento utilizado para professores sem formação inicial de professores foi o grupo Focal, também conhecido por alguns autores como uma entrevista 
http://dx.doi.org/10.5902/1984686X63446

em grupo. Segundo Hamui e Varela (2012), definem-no como um espaço de opinião para captar o sentir, pensar e o viver dos indivíduos, provocando autoexplicações para obtenção de dados qualitativos.

A aplicação dos instrumentos foi precedida por uma reunião que buscou esclarecer sobre as entrevistas. Com esse encontro, também foi igualmente explicitada a natureza e os objetivos da pesquisa, buscando também gerar confiança e um clima psicológico favorável para as entrevistas. Após esse procedimento, seguiu-se a aplicação dos instrumentos em um horário consensual de acordo com a disponibilidade e disposição de cada participante. Por outro lado, um acordo foi alcançado com o grupo focal sobre o local e o horário da reunião, enquanto as entrevistas individuais estavam sendo realizadas. A relevância e validade (conteúdo) dos instrumentos foram determinadas por julgamento de juiz de expertos. Foram avaliados e aprovados com base em critérios pré-estabelecidos em um padrão que obedeceu à escala numérica de avaliação de 1 a 4 e uma escala de avaliação qualitativa que vai de deficiente à excelente (1- DEFICIENTE, 2- REGULAR, 3BOM e 4 - EXCELENTE). Contou-se com a participação de 4 expertos de diferentes universidades. Os critérios de seleção para especialistas foram baseados em experiências e idoneidade que cada um deles conta nas ciências da educação, tanto em termos de trabalho docente como de atividade de pesquisa.

Quadro 1 - Resultados gerais da validação dos instrumentos

\begin{tabular}{|c|c|c|c|c|}
\hline \multirow{2}{*}{ Instrumentos } & \multicolumn{4}{|c|}{ Avaliadores } \\
\cline { 2 - 5 } & Juiz 1 & Juiz 2 & Juiz 3 & Juiz 4 \\
\hline \multirow{2}{*}{ Entrevista } & $\begin{array}{c}\text { (Excelente) sem } \\
\text { comentários }\end{array}$ & $\begin{array}{c}\text { (Bom) com } \\
\text { comentários }\end{array}$ & $\begin{array}{c}\text { (Excelente) com } \\
\text { recomendações }\end{array}$ & $\begin{array}{c}\text { (Excelente) com } \\
\text { recomendações }\end{array}$ \\
\hline \multirow{2}{*}{ Grupo focal } & $\begin{array}{c}\text { (Excelente) sem } \\
\text { comentários }\end{array}$ & $\begin{array}{c}\text { (Bom) com } \\
\text { comentários }\end{array}$ & $\begin{array}{c}\text { (Excelente) com } \\
\text { recomendações }\end{array}$ & $\begin{array}{c}\text { (Excelente) com } \\
\text { recomendações }\end{array}$ \\
\hline
\end{tabular}

Fonte: Campo de pesquisa (2018).

Para a representação quantitativa ao juiz de expertos, foi usado o $\mathrm{V}$ de aiken. $\mathrm{A}$ validade de conteúdo dos instrumentos é analisada através do cálculo das médias de cada item e do teste $V$ de Aiken (PENFIELD e GIACOBBI, 2004) com base nas avaliações quantitativas dos juízes expertos. O coeficiente de validade de conteúdo para $\mathrm{V}$ de aiken foi achado aplicando-se a seguinte fórmula:

$$
V=\frac{S}{(n(c-1))}
$$


http://dx.doi.org/10.5902/1984686X63446

Assim sendo:

$\mathrm{S}=$ somatório dos valores atribuídos por cada experto

$\mathrm{N}$ = número de expertos

$\mathrm{C}=$ número de valores de cada escala de avaliação

Tabela 2 - Resultados V de aiken

\begin{tabular}{|c|c|c|c|c|c|c|c|c|c|c|c|c|c|c|c|c|c|c|c|c|c|}
\hline \multicolumn{8}{|c|}{ Pertinência } & \multicolumn{7}{|c|}{ Clareza } & \multicolumn{7}{|c|}{ Relevância } \\
\hline Item & $\begin{array}{l}\mathrm{J} \\
1\end{array}$ & $\begin{array}{l}\mathrm{J} \\
2\end{array}$ & $\begin{array}{l}\mathrm{J} \\
3\end{array}$ & $\begin{array}{l}\mathrm{J} \\
4\end{array}$ & $\bar{X}$ & $\sum$ & V & $\begin{array}{l}\mathrm{J} \\
1\end{array}$ & $\begin{array}{l}\mathrm{J} \\
2\end{array}$ & $\begin{array}{l}\mathrm{J} \\
3\end{array}$ & $\begin{array}{l}\mathrm{J} \\
4\end{array}$ & $\bar{x}$ & $\sum$ & V & $\begin{array}{l}\mathrm{J} \\
1\end{array}$ & $\begin{array}{l}J \\
2\end{array}$ & $\begin{array}{l}\mathrm{J} \\
3\end{array}$ & $\begin{array}{l}J \\
4\end{array}$ & $\bar{X}$ & $\sum$ & $\mathbf{V}$ \\
\hline Item1 & 3 & 2 & 3 & 3 & $\begin{array}{r}2,7 \\
5\end{array}$ & 11 & $\begin{array}{c}0,7 \\
3\end{array}$ & 3 & 2 & 3 & 3 & $\begin{array}{r}2,7 \\
5\end{array}$ & $\begin{array}{l}1 \\
1\end{array}$ & $\begin{array}{r}0,7 \\
3\end{array}$ & 3 & 2 & 3 & 3 & $\begin{array}{r}2,7 \\
5\end{array}$ & 11 & 0,73 \\
\hline Item 2 & 3 & 2 & 3 & 3 & $\begin{array}{r}2,7 \\
5\end{array}$ & 11 & $\begin{array}{c}0,7 \\
3\end{array}$ & 3 & 2 & 3 & 3 & $\begin{array}{r}2,7 \\
5\end{array}$ & $\begin{array}{l}1 \\
1\end{array}$ & $\begin{array}{r}0,7 \\
3\end{array}$ & 3 & 2 & 3 & 3 & $\begin{array}{r}2,7 \\
5\end{array}$ & 11 & 0,73 \\
\hline Item3 & 3 & 2 & 3 & 3 & $\begin{array}{r}2,7 \\
5\end{array}$ & 11 & $\begin{array}{c}0,7 \\
3\end{array}$ & 3 & 2 & 3 & 3 & $\begin{array}{r}2,7 \\
5\end{array}$ & $\begin{array}{l}1 \\
1\end{array}$ & $\begin{array}{r}0,7 \\
3\end{array}$ & 3 & 2 & 3 & 3 & $\begin{array}{r}2,7 \\
5\end{array}$ & 11 & 0,73 \\
\hline Item4 & 3 & 2 & 3 & 3 & $\begin{array}{r}2,7 \\
5 \\
\end{array}$ & 11 & $\begin{array}{c}0,7 \\
3 \\
\end{array}$ & 3 & 2 & 3 & 3 & $\begin{array}{r}2,7 \\
5 \\
\end{array}$ & $\begin{array}{l}1 \\
1\end{array}$ & $\begin{array}{r}0,7 \\
3 \\
\end{array}$ & 3 & 2 & 3 & 3 & $\begin{array}{r}2,7 \\
5 \\
\end{array}$ & 11 & 0,73 \\
\hline Item5 & 3 & 2 & 3 & 3 & $\begin{array}{r}2,7 \\
5\end{array}$ & 11 & $\begin{array}{c}0,7 \\
3\end{array}$ & 3 & 2 & 3 & 3 & $\begin{array}{r}2,7 \\
5\end{array}$ & $\begin{array}{l}1 \\
1\end{array}$ & $\begin{array}{r}0,7 \\
3\end{array}$ & 3 & 2 & 3 & 3 & $\begin{array}{r}2,7 \\
5\end{array}$ & 11 & 0,73 \\
\hline Item6 & 3 & 2 & 3 & 3 & $\begin{array}{r}2,7 \\
5\end{array}$ & 11 & $\begin{array}{c}0,7 \\
3\end{array}$ & 3 & 2 & 3 & 3 & $\begin{array}{r}2,7 \\
5\end{array}$ & $\begin{array}{l}1 \\
1\end{array}$ & $\begin{array}{r}0,7 \\
3\end{array}$ & 3 & 2 & 3 & 3 & $\begin{array}{r}2,7 \\
5\end{array}$ & 11 & 0,73 \\
\hline $\begin{array}{c}\text { V de } \\
\text { Aiken }\end{array}$ & \multicolumn{7}{|c|}{$\mathbf{0 , 7 3}$} & \multicolumn{7}{|c|}{0,73} & \multicolumn{7}{|c|}{0,73} \\
\hline
\end{tabular}

Fonte: Elaboração própria (2018).

Os princípios éticos da pesquisa estão salvaguardados em conformidade aos códigos e regulamento da Lei $n^{\circ} 20.120$, sobre pesquisa em seres humanos, na qual se guia o comitê de ética científica da Universidade Católica de Maule. Todo o processo relacionado à coleta de informações se procedeu voluntariamente mediante a assinatura de um termo de consentimento informado. O projeto de pesquisa avaliado e aprovado pelo comitê de ética como consta na ata $n^{0}$ 30/2018. Para o processo de análise e interpretação dos dados, inicialmente se fez a transcrição das entrevistas e do grupo focal com recurso a anotações de fichas. Toda a análise das informações foi feita por análise de conteúdo sem recursos a software de processamento informático. A análise de conteúdo é uma técnica de processamento de dados coletados, cujo objetivo é interpretar material de natureza qualitativa, o que garante uma descrição objetiva, sistemática e com a riqueza manifestada no momento da coleta das mesmas (BARDIN, 2009).

\section{Análise e discussão dos resultados}

A natureza qualitativa da pesquisa é refletida tanto através das ferramentas de coleta de informações quanto no processo de análise e apresentação dos resultados. Todas as 
http://dx.doi.org/10.5902/1984686X63446

informações foram processadas sob a análise de conteúdo, entendida também como uma técnica que consiste em uma leitura profunda de cada uma das respostas, onde, codificando cada uma, se alcança um entendimento muito mais preciso sobre o todo (FREITAS e JANISSEK, 2000).

A partir do roteiro de entrevista e do grupo focal, são geradas e definidas as categorias de análise. Algumas são de caráter aprioristico (pré-estabelecidas) e outras emergentes. Para diferenciá-los desde uma perspetiva teórica, nos apoiamos em Cisterna (2005) que considera as categorias aprioristicas como aquelas construídas antes do processo de compilação de informações, ou emergentes, aquelas que surgem do levantamento de referentes significativos da própria investigação. Antes do processo de coleta de informações, a investigação contava com quatro categorias dedutivas ou aprioristicas, e após toda a coleta de informações, duas categorias foram geradas diretamente a partir das informações.

Quadro 2 - Categorias de análise

\begin{tabular}{|c|c|c|}
\hline \multicolumn{2}{|r|}{ Categorias } & Descrição \\
\hline \multirow{4}{*}{ 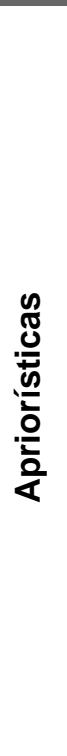 } & $\begin{array}{l}\text { Conhecimento sobre atenção à } \\
\text { diversidade }\end{array}$ & $\begin{array}{l}\text { Esta categoria é entendida como o nível compressivo e } \\
\text { reflexivo que os participantes possuem em relação à } \\
\text { questão da diversidade na educação. }\end{array}$ \\
\hline & $\begin{array}{c}\text { Percepção sobre atenção à } \\
\text { diversidade }\end{array}$ & $\begin{array}{l}\text { Entende-se como o modo pelo qual os participantes } \\
\text { percebem o tema da diversidade a partir de seu juízo } \\
\text { pessoal. }\end{array}$ \\
\hline & $\begin{array}{c}\text { Experiência vivida sobre atenção à } \\
\text { diversidade }\end{array}$ & $\begin{array}{l}\text { Registros e experiências que os participantes têm sobre } \\
\text { situações de diversidade na sala de aula em seu trabalho } \\
\text { docente. }\end{array}$ \\
\hline & $\begin{array}{l}\text { Necessidade de formação para } \\
\text { trabalhar com diversidade }\end{array}$ & $\begin{array}{l}\text { Tem a ver com a constante necessidade de formação e } \\
\text { aprimoramento do professor para uma melhor preparação } \\
\text { do trabalho docente com diversidade na sala de aula. }\end{array}$ \\
\hline \multirow{2}{*}{ 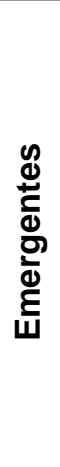 } & $\begin{array}{l}\text { Competências e capacidades } \\
\text { necessárias no que diz respeito à } \\
\text { diversidade }\end{array}$ & $\begin{array}{l}\text { Entende-se como as competências teóricas, didático- } \\
\text { metodológicas e psicológicas que os professores } \\
\text { desenvolveram e que precisam continuar a desenvolver } \\
\text { em sua formação acadêmico-profissional }\end{array}$ \\
\hline & $\begin{array}{l}\text { Debilidades da formação em } \\
\text { relação à diversidade }\end{array}$ & $\begin{array}{l}\text { São todas as insuficiências e fragilidades que sua } \\
\text { formação acadêmico-profissional não potencializou para a } \\
\text { melhor gestão das situações de diversidade em sala de } \\
\text { aula. }\end{array}$ \\
\hline
\end{tabular}

Fonte: Elaboração própria (2018). 
Com base na revisão teórica e em todas as informações referentes à atenção à diversidade na sala de aula que decorrem do discurso dos professores que participaram da pesquisa, são estabelecidas relações não hierarquizadas, porém de associação e interdependência entre as categorias de análise e as ideias centrais da investigação. No processo de coleta de informações, os participantes foram identificados como PAP Professor com Agregado Pedagógico ou com formação inicial de professores e PGF Professor do Grupo Focal para aqueles que não possuem formação inicial de professores. A ilustração a seguir representa o sistema de relação existente entre as categorias.

Figura 1 - Sistema de relação entre as categorias de análise

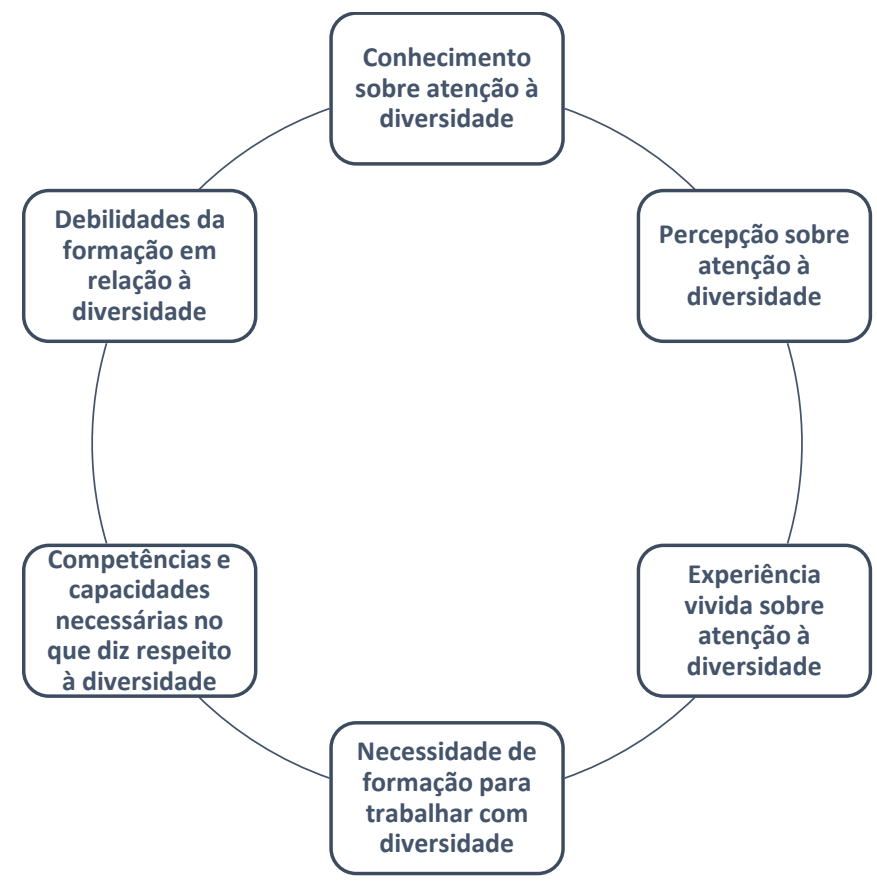

Fonte: Elaboração própria (2018).

Os resultados da pesquisa mostram uma diferença substancial entre o estado de preparação que os professores com formação inicial apresentam em comparação aos professores sem formação inicial. Para os professores que responderam às entrevistas, embora a sua formação profissional seja para o professorado, diante da questão sobre atenção à diversidade, apresentam certo domínio de modo geral e também debilidades na forma como conhecem o assunto e fundamentalmente na forma como lidam com ele na sala de aula. Embora os professores com formação inicial reconheçam a importância da atenção à diversidade e a existência de alunos em situação de vulnerabilidade por conta da diversidade, entendem igualmente que essas crianças não devem ser discriminadas. A definição de diretrizes e estratégias de ação para que as redes de ensino e formação 
http://dx.doi.org/10.5902/1984686X63446

angolanas assegurem o direito de acesso, participação e permanência dos alunos com deficiência e não só, no sistema nacional de educação formal é o principal o objetivo da Política Nacional de Inclusão escolar (ANGOLA, 2017), por isso, quaisquer práticas excludentes na educação, atropelam, não só essa política, assim como negam um direito humano fundamental consagrado.

$\mathrm{Na}$ visão de Sánchez e García (2013) que, ao falarem da diversidade, fundamentalmente a diversidade educacional, afirmam que todos entram, ninguém fica de fora, todas as pessoas são diversas, considerando que diversidade é variedade, sem mais. A ideia de que todas as pessoas são diversas está relacionada à ideia de não discriminar os alunos em sala de aula, como previamente defendido pelos professores. Nas diferentes falas dos professores também ficou evidenciada a necessidade de uma educação cada vez mais inclusiva como um desafio real e necessário para responder à diversidade na sala de aula, mas essa linha de pensamento requer ações concretas e imediatas.

"Na minha opinião, a diversidade educacional tem a ver com o facto colocar todos os alunos em uma única sala de aula". (PAP1).

"Casos de diversidade educacional são realmente registrados em sala de aula". "Na minha opinião, isso tem a ver com o fato de que diferentes professores participam da formação das crianças". (PAP5).

“Na minha visão, a questão da atenção à diversidade é extremamente importante, mas, mais importante do que falar é planejar e implementar ações concretas no sentido de responder a esta situação". (PAP3)

Os professores com formação inicial reconhecem que a sua formação não faz ênfase a problemática da atenção à diversidade e inclusão educacional. Por isso, defendem uma formação docente mais geral no sentido de abranger os mais diversos temas transcendentais à educação atual e, na mesma ocasião, defendem a inserção ao currículo de formação de professores disciplinas específicas sobre inclusão educacional e a existência de um profissional de apoio especializado dentro da escola. Entendem que os professores devem conhecer e dominar o contexto social de aprendizagem e as áreas de desenvolvimento proximal dos alunos conforme defendido por Vygotsky. Em relação às fragilidades assumidas, a mais destacada tem a ver com os recursos didático-pedagógicos e psicológicos que os professores devem dedicar na sala de aula para dar respostas a diferentes situações sobre a necessidade de apoio educacional. Por outro lado, os professores demonstram que o apoio externo à sala de aula e à escola é a solução mais provável, recorrendo habitualmente à família ou a outro profissional (psicólogo) para obter 
http://dx.doi.org/10.5902/1984686X63446

o apoio que se requer. A tendência em buscar apoio fora da escola não é necessariamente uma prática que reflete falta de criatividade interna, supõe-se que esta seja baseada numa função de complementaridade, uma vez que os professores devem em primeira instância esgotar todas as possibilidades de ajuda e intervenção na sala de aula antes de buscar qualquer apoio complementar fora da sala de aula e da escola.

Nesse sentido, referente ao expoxto anteriormente, vários estudos coincidem ao afirmar que é recorrente que professores com formação inicial não estejam preparados e munidos de ferramentas didático-metodológicas necessárias para atender a diversidade e trabalhar em contextos que demandam maior necessidades de inclusão, necessitam de apoios relativamente às condições físicas da sala de aula, a metodologia para atender a diversidade e a relação professor-aluno que se pode obter com o psicólogo ou com a ajuda da família (SAN MARTíN, VILLALOBOS, MUÑOZ Y WYMAN 2017; CALVO 2013).

\footnotetext{
"As competências teóricas para lidar com a diversidade em sala de aula que aprendi na minha formação inicial de professores são as de transmitir conhecimento, usar métodos e recursos de ensino, controlar o comportamento do aluno e o grau de assimilação de conhecimentos em cada aluno" (PAP1).
}

"Eu penso reiteradamente que a fórmula para administrar a diversidade na sala de aula é a formação da professor. Durante minha formação, aprendi alguns conhecimentos que me ajudam a lidar com a diversidade na sala de aula. Prestar mais atenção aos alunos com maior necessidade de apoio" (PAP5)

\begin{abstract}
"Aprendi sobre ZDP (Zona de Desenvolvimento Proximal), SSA (situação social de aprendizagem), diferenças individuais, habilidades inter ou intrapessoais, psicologia geral e de desenvolvimento, psicologia diferencial, inteligências múltiplas, conhecimentos relacionados às necessidades educacionais especial, essas e outras habilidades me permitem lidar, embora de modo superficial com a diversidade na sala de aula" (PAP3)
\end{abstract}

"Eu acho que é necessário que os professores tenham uma formação mais geral e específica para que possam entender os diferentes fenômenos que vão aparecendo no dia-a-dia da sala de aula trabalhar em base da diversidade que cada aluno apresenta ". "Mas também, a diversidade em muitos casos é o resultado de condições sócio-financeiras que muitas famílias apresentam, portanto, essas dificuldades são frequentes em sala de aula e o professor deve estar preparado para enfrentar isso" (PAP2)

Atuar na prática para atender a diversidade é, muitas vezes, uma tarefa complexa para os professores, pois cada aluno apresenta um tipo específico de necessidade de apoio educacional. Segundo Abalde, Muñoz e Rodríguez (2005) consideram três medidas de ações para abordar a diversidade, em primeiro lugar estão as que tomadas ao nível central e com um caráter geral, é caracterizada por regras organizacionais e / ou linhas de trabalho que vão para criar um quadro que permita a realização de atividades para e na diversidade; 
http://dx.doi.org/10.5902/1984686X63446

em segundo lugar, as medidas ao nível de trabalho do professor que permitem a adoção de modelos de trabalho que possibilitem uma verdadeira educação que respeite a pluralidade e a diversidade dos alunos e, em terceiro lugar, as medidas encaminhadas aos alunos que impliquem uma conscientização e autorreflexão de si sobre as peculiaridades de cada um e o respeito necessário por elas.

Embora os professores mostrem disposição em relação à diversidade na sala de aula, apelando à não discriminação e necessidade de uma formação docente mais adequada, quando são confrontados com situações de diversidade que requerem apoio diferenciado aos alunos, reconhecem ser uma tarefa complicada e difícil de gerir dentro de uma uma sala de aula. Alguns desses professores entendem que a diversidade da sala de aula resulta do tipo de educação que cada aluno recebe em seu ambiente familiar. "Entendo que a diversidade educacional tem a ver com os diferentes tipos de
educação que cada criança apresenta, levando em conta que cada aluno
recebe uma educação diferente no contexto familiar." (PAP1)

"São as diferentes posições que os alunos apresentam na sala de aula frente ao processo de aprendizagem." (PAP5)

"Tem a ver com as diferenças dos alunos que se manifestam na sala de aula." (PAP6)

Esse modo de entender a diversidade não é equivocado, mas é uma visão reducionista tendo em conta que a diversidade educacional na sala de aula resulta de múltiplos fatores, pois, nesta pesquisa a diversidade é assumida no seu sentido amplo: diversidade cultural, diversidade social, diversidade do sexo, diversidade étnica racial, diversidade de fatores interpessoais e diversidade de necessidades educacionais especiais. Para apoiar a ideia de uma diversidade mais ampla, DEVALLE e VEGA (1999) apontam que o termo diversidade se refere descritivamente à multiplicidade da realidade ou à pluralidade de realidades.

Em relação aos professores sem formação inicial, mostraram-se menos seguros na sua análise sobre o problema da atenção à diversidade. Alguns reconhecem a caráter de riqueza que a diversidade representa na sala de aula, mas alguns assumem saber pouco ou nada sobre o assunto, é daí que se defende a transferência de todos os alunos com necessidade de apoio educacional para escolas de ensino especial de onde aprenderiam melhor.

"A diferença proporciona riqueza, representa igualmente um desafio diário para qualquer professor que queira ensinar com qualidade". "Se por um lado olhamos para o coletivo considerando o curso como um todo e considrendo o pertencimento da criança ao grupo, ensinando-a a aprender e a conviver com todos, por outro lado, não podemos deixar de garantir uma visão individual do aluno" (PGF5, entrevista fevereiro de 2018, Soyo/Angola) 
http://dx.doi.org/10.5902/1984686X63446

"Na verdade, falar sobre diversidade educacional é um assunto sobre o qual eu sei muito pouco" (PGF1, entrevista fevereiro de 2018, Soyo/Angola).

"Eu acho que aqueles que têm mais dificuldades devem estar em outras escolas que são para educação especial." "Em uma escola especial, eles teriam melhores resultados" (PGF3, entrevista fevereiro de 2018, Soyo/Angola).

A ideia de separar os alunos com maiores necessidades de apoio educacional e pensar que eles só chegam a aprender em escolas especiais é um indicador explícito das práticas de segregação e discriminação.

A abordagem da educação inclusiva refere-se necessariamente ao tratamento do componente da diversidade, porque é consubstancial entre os seres humanos. Nesse sentido, a diversidade deve ser considerada como um valor que reconhece diferenças e respeita a individualidade de cada pessoa, desde a valorização, aceitação e reconhecimento do outro. Essas diferenças trazem para o mundo o que cada pessoa é, não importa o que falta em relação à norma. Da mesma forma, eles dão relevância ao que possuem e ao que são, com os quais enriquecem outras pessoas individualmente e em grupos (CASTILLO, 2015, p.24).

Como refere Ramos (2012, p. 11), "a universalidade da educação somada à extensão da etapa obrigatória implica inexoravelmente a heterogeneidade nas escolas. Diversidade significa a existência ou não de caminhos alternativos de formação que devem ser seguidos". A afirmação anterior deixa clara a inexorável característica heterogênea que desafia a escola diante da diversidade e da inclusão educacional. As diferenças individuais sempre foram e continuarão presentes na sala de aula, mais do que um trabalho adicional, como pensam alguns professores, se deve encarar como uma oportunidade para impulsionar o processo educacional com o uso diversificado de métodos e recursos de ensino e aprendizagem.

Para esses professores, a questão de atenção à diversidade na sala de aula quanto a sua compreensão teórica e prática é mais difícil. Estes confiam o seu êxito na experiência e na iniciativa individual para seguir melhorando através de buscas permanentes. A experiência é sem dúvidas um elemento importante para superar insuficiências e melhorar a performance de qualquer profissional. Mas, com respeito a atenção à diversidade, CALVO (2013) afirma que além da formação pedagógica e ética em que os professores necessitam para educar em e para a diversidade, a formação didática é fundamental, uma vez que essa faceta possibilita ao professor o conhecimento e o manejo adequado de um amplo repertório de estratégias didáticas que permitam chegar através de uma metodologia mais apropriada às condições específicas dos alunos de forma que possa atender às suas necessidades. 
http://dx.doi.org/10.5902/1984686X63446

"Eu não tenho nenhuma formação pedagógica (formação de professores), mas acho que a experiência me ajudará a entender e resolver os problemas que tem a ver com a diversidade educacional" (PGF1, entrevista fevereiro de 2018, Soyo/Angola).

"Sou técnico informático de formação, nunca tive formação de professores, mas tento investigar e tentar me aperfeiçoar. É difícil" (PGF2, entrevista fevereiro de 2018, Soyo/Angola).

"Eu não fiz formação inicial de professores, tudo que conheço hoje é resultado da experiência" (PGF3, entrevista fevereiro de 2018, Soyo/Angola).

Especificamente sobre a perceção que esses professores têm a respeito da diversidade no contexto educacional, embora alguns sejam mais contundentes ao dizer que não têm ideia sobre o assunto e que o mesmo é uma novidade, outros se esforçam definilo. O consideram como um olhar face às dificuldades que os alunos apresentam e a não discriminação na sala de aula.

"Não tenho certeza do que vou dizer, mas acho que diversidade tem a ver com um conjunto de problemas que o professor pode enfrentar na sala de aula" (PGF1, entrevista fevereiro de 2018, Soyo/Angola).

"Nada, eu não entendo e não tenho idéia sobre diversidade. "Sério, eu gostaria de aprender sobre esse assunto" (PGF2, entrevista fevereiro de 2018, Soyo/Angola).

"Eu entendo que todos devem ser ensinados sem discriminação alguma". "Mas eu não sei especificamente o que é diversidade educacional, é novo para mim" (PGF3, entrevista fevereiro de 2018, Soyo/Angola).

Em geral, a ideia de aceitação para todas as crianças é interessante, respeitar cada uma na sua condição de pessoa diferente é fundamental para um processo educativo que considera as diferenças individuais como oportunidade de fazer cada vez melhor. $\mathrm{O}$ respeito pelas diferenças é um elemento-chave para abordar a diversidade. "Os alunos com necessidades educativas especiais associadas ou não a deficiência têm os mesmos direitos, oportunidades e acessibilidade ao currículo escolar como qualquer aluno" (ANGOLA, 2017, p. 3682).

"Sabemos que em uma sala de aula nem todos aprendem da mesma forma, nem as mesmas coisas e nem ao mesmo tempo, mas estamos cientes de que todos aprendem, especialmente quando temos uma proposta adequada para as necessidades das crianças." . "Mesmo os alunos com deficiência intelectual estão nessa lógica e necessitam uma adequação do currículo" (PGF5, entrevista fevereiro de 2018, Soyo/Angola).

"É o que acontece quando em uma sala de aula os alunos aprendem em diferentes ritmos, de diferentes maneiras e em diferentes momentos". Nós devemos administrar esta situação com a aplicação de estratégias metodológicas apropriadas" (PGF6, entrevista fevereiro de 2018, Soyo/Angola). 
http://dx.doi.org/10.5902/1984686X63446

Mas, por outro lado, um pormenor a levar em consideração é questão de alguns professores que relatam nunca ter vivido uma experiência de diversidade na sala de aula. Diante da impossibilidade de que isso seja verdade, pode-se dizer que alguns desses professores não são capazes de reconhecer a heterogeneidade de um curso e as situações de diversidade em sala de aula, o que supostamente os leva a afirmar categoricamente em nunca ter havido alunos com necessidades de apoio educativo em sala de aula durante seu labor docente. A diversidade é uma oportunidade para que educadores mobilizem esforços para a multiplicação de resultados, a prática demonstra a riqueza desse campo, ao mesmo tempo que essa temática gera interesse as mais diversas áreas de conhecimento e atuação, tanto na educação como na psicologia, na ciência política e social (WENDT e SCHOLL, 2011).

"Não. Não sei se já tive ou não algum aluno com necessidade de apoio educativo" (PGF2, entrevista fevereiro de 2018, Soyo/Angola).

"Não. Nunca tive" (PGF5, entrevista fevereiro de 2018, Soyo/Angola).

Diante de todas as dificuldades apontadas pelos professores sem formação inicial de professores, reconhecem e defendem que todas as carreiras acadêmicas deveriam abordar a questão da atenção à diversidade e à inclusão educacional, uma vez que a atenção à diversidade é necessária dentro e fora da escola. Defendem que a inserção de mais disciplinas que estudam o comportamento humano contribuiriam muito, embora a qualidade dos formadores de futuros professores em relação à atenção à diversidade seja também uma questão a ser levada em conta. Em reconhecimento às suas dificuldades, alguns professores defendem a formação contínua (seminários de capacitação e refrescamento), principalmente em termos de diagnóstico e intervenção das dificuldades de aprendizagem, enquanto outros defendem uma transferência total de todos os alunos com necessidades de apoio educativo para escolas especiais. A visão discriminatória assumida por alguns professores representa apenas um déficit da sua formação, um aspeto necessário para que eles estejam um pouco mais dentro da visão inclusiva que a educação atual exige.

\footnotetext{
"Independentemente do fato de que não tenha formação inicial, acho que todas as especialidades de formação devem lidar com esse assunto, a diversidade está dentro e fora da sala de aula" (PGF1, entrevista fevereiro de 2018, Soyo/Angola).

"Eu acho que uma disciplina relacionada à diversidade seria muito importante, talvez uma que estuda o comportamento humano" (PGF2, entrevista fevereiro de 2018, Soyo/Angola).
} 
http://dx.doi.org/10.5902/1984686X63446

"Há uma falta de formadores de professores capazes de formar futuros professores em relação à atenção da diversidade educacional em sala de aula" (PGF5, entrevista fevereiro de 2018, Soyo/Angola).

É importante salientar que quanto mais se assume a educação inclusiva como um compromisso com a diversidade em uma unidade de formação de professores, maior será a probabilidade de se aprender a realizar a tarefa educacional de diferentes maneiras e face às diferenças.

Aprender com os outros, compartilhar conhecimentos, habilidades, reflexões, crenças [...] para uma educação de qualidade, uma educação acessível a todos, se situa em outro lugar, no qual é possível avançar para uma educação mais inclusiva. E nessa linha, as instituições, responsáveis pela formação de futuros educadores, agora têm o desafio de implementar uma orientação inclusiva de educação em nossos currículos (FORTEZA, 2010, p. 8).

\begin{abstract}
No entanto, tendo em vista a demanda de formação de professores para a diversidade, o contexto geral em que as mudanças são orientadas deve ser levado em conta. Dentro desse contexto de otimização da educação e o avançar para uma formação de professores com componentes de educação inclusiva, é fundamental partir da análise da realidade do contexto, isso permite saber onde se está e ter clareza para onde se está indo, facilita a implementação de ambientes de aprendizagem apropriados, se abrem possibilidades para avaliar os processos que ocorrem no centro de formação e reforça com maior convicção tudo o que é positivo na prática educativa da formação profissional (CASTILLO, 2015, p. 15).
\end{abstract}

Os principais resultados da discussão desta pesquisa levam ao reconhecimento da necessidade de uma transformação do sistema educativo e, especialmente, das escolas, visando atender as demandas de uma educação mais inclusiva. A formação de professores é uma questão transcendental para responder à diversidade dos alunos que estão presentes em sala de aula. Portanto, a preocupação da educação inclusiva busca flexibilizar e transformar as práticas pedagógicas e a organização das escolas para atender às diversas necessidades educativas dos alunos e que são consequência de múltiplos fatores. Acreditamos que, o enveredar por uma educação para a diversidade, por uma educação de qualidade para todos, exige um corpo docente engajado, comprometido e competente, com ferramentas que permitam atender todos os alunos da sala de aula e a garantir o máximo de aprendizagens independentemente das características que apresentam; em suma, um corpo docente preparado para gerir o sucesso em salas de aula heterogêneas. 
http://dx.doi.org/10.5902/1984686X63446

\section{Considerações finais}

Diante dos resultados encontrados e face toda a consulta bibliográfica realizada sobre a preparação de professores do ensino primário, no município do Soyo, sobre atenção à diversidade em sala de aula, conclui-se:

A preparação de professores com e sem formação inicial de professores em relação à diversidade reflete inadequações, uma vez que demonstraram debilidades no conhecimento teórico e de gestão didático-metodológica em relação à atenção à diversidade em sala de aula.

A formação inicial e permanente dos professores para o ensino primário não capacita os professores e futuros professores no que diz respeito à diversidade, levando-os a responder inadequadamente às necessidades de apoio educacional requeridas pontualmente ou continuamente pelos alunos, caracterizando-se por ser débil, assistemática e de iniciativa individual do professor guiada por motivações próprias para o crescimento profissional.

Quanto à perceção da prática em sala de aula, os professores com formação inicial reconhecem a diversidade como representação de riqueza e variedade, e uma oportunidade de implementar metodologias diversificadas de ensino em sala de aula, ao passo que professores sem formação inicial defendem principalmente que os alunos com necessidades de apoio educacional sejam transferidos para uma escola especial.

Finalmente, os professores de ambas as categorias enfrentam grandes dificuldades de gestão pedagógico-metodológica, na prática, uma vez que todo o seu processo de formação não inclui mecanismos didáticos de intervenção diante de situações mais concretas de diversidade em sala de aula, daí, acreditamos que, a Repartição Municipal da Educação em colaboração com as direções das escolas, pode promover atividades de formação e superação dos profissionais da educação face às demandas de uma educação mais inclusiva e que atenda a diversidade. Por isso, os resultados dessa pesquisa, podem servir de aporte e, a partir das suas reflexões, redirecionar os seminários de capacitação para o início de cada ano letivo, fazendo a devida ênfase na questão da atenção à diversidade. A realização e os resultados dessa pesquisa são também uma chamada de atenção para alertar sobre a necessidade de se começar a pensar numa educação de e para todos, independentemente de qualquer diferença.

Outrossim, o estudo mostra algumas limitações, por exemplo, não foram encontrados pesquisas regionais ou nacionais para ajudar a contrastar os resultados, isso teria 
http://dx.doi.org/10.5902/1984686X63446

contribuído melhor para discutir os resultados obtidos aqui, no entanto, esses resultados preliminares podem ser considerados como uma referência para futuras pesquisas e, incluindo futuras comparações com base em estudos dessa tendência. Outra limitação é o fato de contar com uma amostra não probabilística, o que não nos permite generalizar os nossos resultados obtidos para outros contextos, mas isso não invalida a investigação, visto que a intenção do estudo foi investigar de forma exploratória. Sugere-se, no futuro, a realização de pesquisas mais abrangentes e com distintas estratégias metodológicas, a ponto de se ter mais escolas e mais professores para a amostra. O conhecimento gerado a partir desta pesquisa servirá de base para qualquer estudo ou análise do tema atenção à diversidade. É também um convite para que os profissionais da educação reflitam criticamente sobre a formação de professores em relação à diversidade na sala de aula.

\section{Referências}

ABALDE, E.; MUÑOZ, J. y RODRÍGUEZ, E. Calidad educativa y atención a la diversidad desde un marco legislativo en la comunidad autónoma de Galicia. Rev. Galegoportuguesa de psicología y educación, 12(10), 1138-1663, 2005. Disponível em: https://core.ac.uk/download/pdf/61900598.pdf. Acesso em: 13 de jul. de 2017.

ANGOLA. Decreto Presidencial $n^{\circ}$ 187/17, de 16 de agosto de 2017. Dispõe sobre a Política Nacional de Educação Especial Orientada para a Inclusão Escolar. Luanda, I série, n¹40. Diário da República de Angola, 2017.

ANGOLA. Lei 17/16, de 7 de outubro. Aprova a Lei de Bases do Sistema de Rducação e ensino de Angola, que estabelece os princípios e as bases gerais do Sistema de Educação e Ensino. Luanda, I série, n 170. Diário da República de Angola, 2016.

ANGOLA. Lei complementar $n^{\circ}$ 30/20, de 12 de agosto. Altera a lei 17/16, de 7 de outubro - Lei de Bases do Sistema de educação e Ensino.Luanda, I série, $n^{\circ} 123$. Diário da República de Angola, 2020.

ARAQUE, H. N. y BARRIO DE LA PUENTE, J. L. Atención a la diversidad y desarrollo de procesos educativos inclusivos. Prisma social, Madrid (4) pp. 1-37. 2010. Disponível em: https://www.isdfundacion.org/publicaciones/revista/pdf/13_N4_PrismaSocial_natividad_jos eluis.pdf. Acesso em: 17 de nov de 2017.

ARIAS, F. G. EI Proyecto de Investigación: Introducción a la metodología científica. 6ª Ed. Caracas: editorial episteme, C.A, 2012.

ARTILES, A. J. e KOZLESKI, E. B. Promessas e trajetórias da Educação Inclusiva: notas críticas sobre pesquisas futuras voltadas a uma ideia venerável. Práxis Educativa, Ponta Grossa, v. 14, n. 3, p. 804-831, set./dez. 2019. Disponível em: http://www.revistas2.uepg.br/index.php/praxiseducativa. Acesso em: 13 de set. de 2019. 
http://dx.doi.org/10.5902/1984686X63446

BARDIN, L. Análise de Conteúdo. Lisboa, Portugal; Edições 70, LDA, 2009.

BARRIO DE LA PUENTE, J. L. Hacia una Educación Inclusiva para todos, Revista Complutense de Educación, Madrid, v.20 n.1 p. 13-31, 2008. Disponível em: https://revistas.ucm.es/index.php/RCED/article/view/RCED0909120013A. Acesso em: 17 de nov. de 2017.

BERGERON, B. S. Enacting a culturally responsive curriculum in a novice teacher's classroom. Urban Education, v.43, n.1, p.4-28, 2008. Disponível em:

https://www.scirp.org/journal/paperinformation.aspx?paperid=108221. Acesso em: 20 de jul. de 2020.

CALVO, G. La formación de docentes para la inclusión educativa. Montevideo, v.6, n.1, pp. 1-22, 2013. Disponível em: http://www.scielo.edu.uy/pdf/pe/v6n1/v6n1a02.pdf. Acesso: 16 de nov. de 2017.

CALVO, G. La formación de docentes para la inclusión educativa. Teacher training for inclusive education. Páginas de Educación, [S. I.], v. 6, n. 1, p. 19-35, 2015. Disponível em: https://revistas.ucu.edu.uy/index.php/paginasdeeducacion/article/view/525. Acesso em: 13 abr. 2021.

CASTILLO, B. C. La educación inclusiva y lineamientos prospectivos de la formación docente: una visión de futuro. Actualidades Investigativas en Educación. Costa Rica, V.15, n.2, p. 1-33, 2015. Disponível em: https://revistas.ucr.ac.cr/index.php/aie/article/view/18534. Acesso em: 17 de nov. de 2017.

CISTERNA, C. F. Categorización y triangulación como procesos de validación del conocimiento en investigación cualitativa. Theoria, Chile, v.14, n.1, p.61-71, 2005. Disponível em: https://www.redalyc.org/articulo.oa?id=29900107. Acesso em: 10 de out. 2018.

DEVALLE DE RENDO, A. y VEGA, V. Una escuela en y para la diversidad. El entramado de la diversidad, Argentina, Aique Grupo Editor, 1999.

DÍAZ, B. L.; TORRUCO, G. U.; MARTÍNEZ, H. M. \& VARELA, R. M. La entrevista, recurso flexible y dinámico. Investigación en educación médica, v.2, n.7, p. 162-167, 2012. Disponível em: http://www.scielo.org.mx/scielo.php?script=sci_arttext\&pid=S200750572013000300009\&Ing=es\&tIng=es. Acesso em: 04 de dez. 2018.

FORTEZA, D. La formación del profesorado en y para la educación inclusiva desde la perspectiva de la convergencia europea. 2010. Recuperado de http://www.centrodocumentaciondown.com/uploads/documentos/36b7c169f84273904d06ad 1eac3523b10aed83f9.pdf. Acesso em 17 de nov. 2017.

FREITAS, H. y JANISSEK, R. Análise léxica e Análise de Conteúdo: técnicas complementares, seqüenciais e recorrentes para análise de dados qualitativos. Porto Alegre: Sphinx, 2000.

GAVIRA, S. A \& OSUNA, J. B. La triangulación de Datos como estrategia en investigación educativa. Revista de Medios y Educación, Espanha, n.47, p. 3-88, 2015. Disponível em: https://recyt.fecyt.es/index.php/pixel/article/view/61672. Acesso em: 17 de nov. de 2018 
http://dx.doi.org/10.5902/1984686X63446

GIMENO, J. La construcción del discurso acerca de la diversidad y sus prácticas. En AA. VV. Atención a la diversidad, Barcelona n.81, p. 11-35, 2000. Disponível em:

https://altascapacidadescse.org/cse/pdf/la_construccion_del_discurso.pdf. Acesso em: 17 de nov. 2017.

GOMES, A. A. Apontamentos sobre a pesquisa em educação: usos e possibilidades do grupo focal. EccoS - Revista Científica, São Paulo, v. 7, n. 2, p. 275-290, jul./dez. 2005. Disponível em: https://www.redalyc.org/pdf/715/71570203.pdf. Acesso em: 25 de mar. 2021.

HAMUI, S. A. y VARELA, R. M. La técnica de grupos focales. Inv Ed Med, México, v.2, n.1, p.55-60, 2013. Disponível em: http://www.scielo.org.mx/pdf/iem/v2n5/v2n5a9.pdf. Acesso em: 20 de nov. de 2017.

HERNÁNDEZ, R; FERNÁNDE, C \& BAPTISTA, P. Metodología de la investigación, 6a Ed. México: MCGRAW-HILL, 2014.

MARTIN, C. S. et al. Formación inicial docente para la Educación Inclusiva. Análisis de tres programas chilenos de pedagogía en Educación Básica que incorporan la perspectiva de la educación inclusiva. Calidad en la educación, Santiago, n. 46, p. 20-52, 2017. Disponível em: https://scielo.conicyt.cl/pdf/caledu/n46/0718-4565-caledu-46-00020.pdf. Acesso em: 13 abr. 2021.

MARTIN, C.; VILLALOBOS, C.; MUNOZ, C. y WYMAN, I. Formación inicial docente para la Educación Inclusiva: Análisis de tres programas chilenos de pedagogía en Educación Básica que incorporan la perspectiva de la educación inclusiva. Calidad en la educación. Chile, n.46, pp.20-52, 2017. Disponivel em: https://scielo.conicyt.cl/pdf/caledu/n46/07184565-caledu-46-00020.pdf. Acesso em: 15 de dez. 2019.

PENIELD, R.D., y GIACOBBI, P.R. Applying a score conidence interval to Aiken's item content-relevance index. Measurement in Physical Education and Exercise Science, v.8, n.4, p.213-225, 2004. Disponível em:

https://www.tandfonline.com/doi/abs/10.1207/s15327841mpee0804_3. Acesso em: 10 de jul. de 2020.

RAMOS, C. J. Cuando se habla de diversidad ¿de qué se habla? Una respuesta desde el sistema educativo, Revista Interamericana de Educación de Adultos Año 34, México, $n^{\circ} 1$, 2012. Disponível em: https://www.redalyc.org/pdf/4575/457545090006.pdf. Acesso em: 20 de nov. de 2017.

RuÍZ, Q. P. La evolución de la atención a la diversidad del alumnado de educación primaria a lo largo de la historia. Temas para la Educación. Revista digital para profesionales de la enseñanza, n.8, 2010. Disponível em:

https://www.feandalucia.ccoo.es/docu/p5sd7241.pdf. Acesso em: 24 de ago. De 2018.

SÁNCHEZ, S. M. y GARCÍA M. R. Diversidad e inclusión educativa: aspectos didácticos y organizativos, [s.n], Madrid, España: catarata, 2013.

SPRADLEY, J. Participant Observation, Nueva York: Rinehart \& Winston, 1980. 
WENDT, G. W.; SCHOLL, R. C. Formação de professores para a diversidade: enfrentando o desafio. Pro-Posições, Campinas, v. 22, n. 3, p. 209-212, 2011. Disponível em: https://www.scielo.br/scielo.php?script=sci_arttext\&pid=S010373072011000300015. Acesso em: 21 nov. 2020.

\section{Notas}

1 Este estudo contou com o financiamento da AGCID - Agencia de Cooperación Internacional para el Desarrollo de Chile (AGCID), através da bolsa de estudos Nelson Mandela.

$2 \mathrm{Na}$ Lei de Bases do Sistema de Educação e Ensino de Angola, considera-se de Ensino Primário ao nível de ensino que tem a duração de 6 anos e têm acesso, ao mesmo, as crianças que completem, pelo menos, 6 anos de idade no ano da matrícula. LBSEE - Lei de Bases do Sistema de Educação e Ensino, lei 17/16, de 7 de outubro alterada pela lei 32/20.

(c) (i) (9)

This work is licensed under a Creative Commons Attribution-NonCommercial 4.0 International (CC BY-NC 4.0) 